\title{
THE REACTION OF TETRAMETHYLSILANE WITH BORON TRIBROMIDE
}

\author{
Jaroslaw Lewkowski*1 and Michel Vaultier ${ }^{2}$ \\ 'Department of Organic Chemistry, University of Lodz, Narutowicza 68, 90-136 Lodz, Poland \\ - Synthese et Electrosynthese Organique, UMR 6510 associe au CNRS, Universite Rennes 1, \\ F-35042 Rennes cedex, France
}

\begin{abstract}
The reaction of tetramethylsilane with boron tribromide in deuterochloroform in ambient temperature or at $40^{\circ} \mathrm{C}$ led to bromotrimethylsilane (3) and to dibromomethylborane (4). Identity of products was confirmed by NMR spectroscopy. Analogical reaction carried out in 1,3-dichloropropane allowed to separate products of the reaction and to obtain them in $68 \%$ and $59 \%$ yields respectively.
\end{abstract}

Key words: Tetramethylsilane, boron tribromide, bromine replacement, dibromomethylborane

Tetramethylsilane is known as a stable compound and for this reason this reagent is commonly used as an internal reference in NMR spectroscopy. However, there are some examples of its reaction catalysed by aluminium chloride ${ }^{1.2}$ to give chlorotrimethylsilane.

The analogue of tetramethylsilane - tetramethylstannane reacts more easily with halogenating agents. Some papers have been published. which described various aspects of its reaction with boron tribromide, which gave dibromomethylborane. ${ }^{3-5}$ Aryltrimethylstannanes were claimed to react with boron trichloride to yield dichloromethylborane. ${ }^{6.7}$ The synthesis of dibromomethylborane from silyl compound was reported only once from boron tribromide and tris-(trimethylsilanyl)amine. ${ }^{8}$

To our best knowledge, there are no examples for the reaction between tetramethylsilane and boron trihalide. Literature reports some successful attempts of the reaction between aryltrimethylsilanes ${ }^{9.10}$ or vinyltrialkylsilanes " and boron trihalides to give aryl- or vinylhaloboranes respectively.

In this paper, we would like to report the first example of the reaction between tetramethylsilane and boron tribromide providing bromotrimethylsilane (4) and dibromomethylborane (3) in fair yields. The reaction is a possible new method for synthesis of dibromomethylborane.

The reaction between tetramethylsilane (1) and boron tribromide (2) was carried out directly in the NMR tube in deuterochloroform at room temperature for several days. After a one day of storage, NMR analysis showed the formation of two new compounds and, after 5 days, the reaction was complete. $H$ NMR signals appeared at $\delta_{\mathrm{H}}=0.58$ and $-2.8 \mathrm{ppm},{ }^{13} \mathrm{C}$ NMR - at $\delta_{\mathrm{C}}=4.13$ and $(-0.62) \mathrm{ppm}$. "B NMR and ${ }^{29} \mathrm{Si} \mathrm{NMR}$ gave resonances at $\delta_{\mathrm{B}}=62.95 \mathrm{ppm}$ and at $\delta_{\mathrm{si}}=27.2 \mathrm{ppm}$ respectively.

These data allowed to characterize products formed. According to Ralph and Landucci ${ }^{12}$ as well as to an NMR data compilation ${ }^{14}$, bromotrimethylsilane 3 gives ${ }^{1} \mathrm{H}$ NMR signal at $\delta_{\mathrm{H}}=0.58 \mathrm{ppm},{ }^{29} \mathrm{Si}$ NMR signal at $\delta_{\mathrm{Si}}=26.5 \mathrm{ppm},{ }^{13} \mathrm{C}$ NMR shift value is quoted ${ }^{11,13}$ to occur at $\delta_{\mathrm{C}}=4.6 \mathrm{ppm}$.

Our NMR measurements of post-reaction mixture showed $\delta_{\mathrm{H}}=0.58 \mathrm{ppm}, \delta_{\mathrm{Si}}=27.2 \mathrm{ppm}$ and $\delta_{\mathrm{C}}=4.13 \mathrm{ppm}$, so values so close to published observations that they show undoubtedly that one of two products is bromotrimethylsilane 3 .

The second compound, which in our opinion is dibromomethylborane 4, gave a ' $\mathrm{H}$ NMR signal at $\delta_{\mathrm{H}}=-\mathbf{2 . 9}$ ppm, ${ }^{15} \mathrm{C}$ NMR signal at $\delta_{\mathrm{C}}=-0.62 \mathrm{ppm}$ and a ${ }^{11} \mathrm{~B}$ NMR resonance occurred at $\delta_{\mathrm{B}}=62.95 \mathrm{ppm}$.

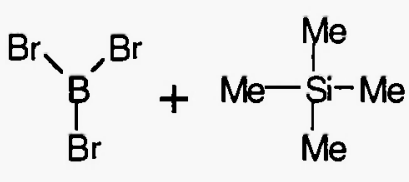

1

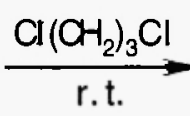

2<smiles></smiles>

3<smiles>C[Si](C)(C)Br</smiles>

4

Scheme 1

A dcompilation ${ }^{15}$ as well as Nöth $e t$ al quoted a "B NMR chemical shift $\delta_{B}=62.5 \mathrm{ppm}$, which fits perfectly with our observation. Some disagreement with literature data appeared in the case of the 'H NMR resonance, which according to $\mathrm{Nöth}^{4}$ appears at $\delta_{\mathrm{H}}=-1.42 \mathrm{ppm}$ in $\mathrm{CCl}_{4}$. Our measurements were performed in 
deuterochloroform and this might be a reason for the difference observed. As for ${ }^{i 3} \mathrm{C} \mathrm{NMR}$, we found no data in the literature for carbon chemical shift of dibromomethylborane.

When the reaction was carried out at $40^{\circ} \mathrm{C}$, it was completed within 36 hours. Products were separated by fractional distillation, but as boiling points of deuterochloroform $\left(b p=60.9^{\circ} \mathrm{C}\right)^{16}$ and dibromomethylborane $\left(b p=58-60^{\circ} \mathrm{C}\right)^{8}$ are very close, we obtained a mixture of these two compounds. Bromotrimethylsilane was isolated as the last fraction boiling at $79-81{ }^{\circ} \mathrm{C}\left({ }^{1 i t^{16}}=79^{\circ} \mathrm{C}\right)$.

When the reaction was carried out in 1,3-dichloropropane, the separation of the products was much easier as the solvent boil at higher temperature. Dibromomethylborane was isolated by fractional distillation, collected at $59-61{ }^{\circ} \mathrm{C}$ in $53 \%$ yield. Bromotrimethylsilane was isolated as above in $68 \%$ yield.

Yields are maybe not satisfactory, but the reaction provides useful reagents starting from cheap starting materials.

\section{Experimental section}

Deuterochloroform (Merck), tetramethylsilane (Fluka) and boron tribromide (Aldrich) were used as received. 1,3-Dichloropropane was routinely distilled and dried prior to use. All NMR spectra were recorded on a Brucker $300 \mathrm{AC}$ spectrometer.

Reaction between tetramethylsilane (1) and boron tribromide (2) in deuterochloroform

Tetramethylsilane $(89 \mathrm{mg}, 1 \mathrm{mmol})$ was dissolved in deuterochloroform $(3 \mathrm{~mL})$ and then boron tribromide $\left(25 \mathrm{mg}, 1 \mathrm{mmol}\right.$ ) was added. The reaction was stored for 5 days at room temperature or heated at $40^{\circ} \mathrm{C}$ for 36 hrs. The progress of the reaction was monitored by ${ }^{1} \mathrm{H}$ and ${ }^{11} \mathrm{~B}$ NMR spectroscopy. The mixture was separated by distillation, first fraction was collected at $59-61^{\circ} \mathrm{C}$. It was the solution of dibromomethylborane 4 and deuterochloroform.

Reaction between tetramethylsilane (1) and boron tribromide (2) in 1,3-dichloropropane

Tetramethylsilane $(89 \mathrm{mg}, 1 \mathrm{mmol})$ was dissolved in 1,3-dichloropropane $(3 \mathrm{~mL})$ and then boron tribromide (25 $\mathrm{mg}, 1 \mathrm{mmol}$ ) was added. The mixture was stirred under nitrogen for 5 days. Then, the mixture was separated by fractional distillation. The first fraction was collected at $59-61^{\circ} \mathrm{C}$ and identified as dibromomethylborane 4 . The second fraction, bromotrimethylsilane 3 , was collected at $79-81^{\circ} \mathrm{C}$.

Bromotrimethylsilane 3

Yield $68 \%$. Bp. $79-81^{\circ} \mathrm{C}$, lit $^{16} 79^{\circ} \mathrm{C}, \mathrm{n}_{\mathrm{D}}=1.4235$, lit $^{16} 1.4240$.

'H NMR (300 MHz, CDCl $): \delta 0.52\left(\mathrm{CH}_{3}\right) .{ }^{13} \mathrm{C} \mathrm{NMR}\left(75 \mathrm{MHz}, \mathrm{CDCl}_{3}\right): \delta 4.13\left(\mathrm{CH}_{3}\right) .{ }^{29} \mathrm{Si} \mathrm{NMR}(59 \mathrm{MHz}$, $\left.\mathrm{CDCl}_{3}\right): \delta 27.3$.

Dibromomethylborane 4.

Yield 59\%. Bp. 59-61 ${ }^{\circ} \mathrm{C}, \mathrm{lit}^{8}{ }^{8} 58-60^{\circ} \mathrm{C}$. ' $\mathrm{H}$ NMR $\left(300 \mathrm{MHz}, \mathrm{CDCl}_{3}\right): \delta-2.9\left(\mathrm{CH}_{3}\right) .{ }^{13} \mathrm{C}$ NMR $(75 \mathrm{MHz}$, $\left.\mathrm{CDCl}_{3}\right): \delta-0.62\left(\mathrm{CH}_{3}\right)$. "'B NMR $\left(96 \mathrm{MHz}, \mathrm{CDCl}_{3}\right): \delta 62.95$.

Acknowledgement. Authors wish to thank Dr. Sourisak Sindbandhit (CRMPO - Rennes) for his assistance in recording of NMR spectra.

\section{References and notes:}

1. Bordeau, M.; Djamei, S.M.; Calas, R.; Dunogues, J. Bull.Soc.Chim.Fr., 1985, 488

2. Bordeau, M.; Djamei, S.M.; Calas, R.; Dunogues, J. J.Organomet.Chem., 1985, 288, 131

3. Nöth, H.; Vahrenkamp, H. J.Organomet.Chem., 1968, 11,399

4. Nöth, H.; Vahrenkamp, H. J.Organomet.Chem., 1968, 12, 23

5. Gerrard, W.; Mooney, E.F.; Rees, R.G. J.Chem.Soc., 1964, 740

6. Chivers, T.; David, B. J.Organomet.Chem., 1968, 13, 177

7. Chambers, R.D.; Chivers, T.J.Chem.Soc., 1965, 3933

8. Barlos, K.; Noeth, H. Chem.Ber., 1977, 110, 3460

9. Haubold, W.; Herdtle, J.; Gollinber, W.; Einholz, W. J.Organomet.Chem., 1986, 315, 1

10. Gross, U.M.; Bartels, M.; Kaufmann, D. J.Organomet.Chem., 1988, 34t, 217

11. Mikhail, I.; Kaufmann, D. J.Organomet.Chem., 1990, 398, 53

12. Ralph, J.; Landucci, L.L. J.Org.Chem., 1983, 48,3884

13. Breitmeier, E.; Voelter, W. Carbon-13 NMR Spectroscopy, VCH, Weinheim 1989, 293

14. Harsmann, H. "Si NMR Spectroscopic Results in Oxygen-17 and Silicon-29 NMR, NMR Basic Principles and Progress series (Ed Diehl, P.; Fluck, E.; Kosfeld, R), Springer Verlag 1981, 202

15. Nöth, H.; Wrackmeyer, B. Nuclear Magnetic Resonance Spectroscopy of Boron Compounds, NMR Basic Principles and Progress series (Ed Diehl, P.; Fluck, E.; Kosfeld, R), Springer Verlag, 1978, 132,372

16. Aldrich Catalogue of Fine Chemicals 1999-2000, 285, 392

Received: November 8, 2000 - Accepted: November 30, 2000 Accepted in publishable format: November 31, 2000 